\title{
Community Based Essential Newborn Care Practices and Associated Factors among Women Who Gave Birth at Home in Last Twelve Months in Amaro Woreda, Southern Ethiopia, 2019
}

Mamush Agonafir

Save the Children Ethiopia

Mulugeta Shegaze Shimbre ( $D$ mulsheg@yahoo.com )

Arba Minch University https://orcid.org/0000-0002-4146-275X

Sultan Hussen

Arba Minch University

Gebremaryam Temesgen

Arba Minch University

Goytom Girmay

Arba Minch University

Behailu Tsegaye

Arba Minch University

Woiynshet Gebretsadik

Arba Minch University

Belay Boda

Arba Minch University

Teshale Fikadu

Arba Minch University

Research article

Keywords: community based cross sectional study, essential newborn care practices Amaro district

Posted Date: August 23rd, 2019

DOI: https://doi.org/10.21203/rs.2.13490/v1

License: (c) (1) This work is licensed under a Creative Commons Attribution 4.0 International License.

Read Full License 


\section{Abstract}

Introduction:- Significant numbers of women are giving birth at home; in this case community based newborn care is a means of bringing life-saving care to mothers and newborns at the community level. However, practice is challenging within the Ethiopian health system. Objective:- The aim of this study was

to assess prevalence of community based newborn care practices and its associated factors among women who gave birth at home in Amaro Woreda, southern Ethiopia, 2019. Methods:- Across-sectional study was conducted on 490 women in the reproductive age groups of 15-49 in Amaro district and by using simple random sampling technique individual was recruited. Data collected through face-to-face interview at household level. EpiData version 3.1 statistical software was used for entry and SPSS version 20 for was used for data cleaning, management and analysis. Bi-variate and multivariate logistic regression analysis employed for analysis of factors associated with Community based newborn care practices. Results:- A total 490 of study participants were included in the analysis and only $29 \%$ practiced community based essential newborn care. Educational status of father [AOR=2.28; 95\%Cl:1.07-4.84] \& mother [AOR=0.35; 95\% Cl: 0.16-0.75], last delivery assisted by relative/friends [AOR=3.58; $95 \% \mathrm{Cl}: 1.66-$ 7.73], having awareness about Community based newborn care [AOR=3.49; 95\% Cl: 2.11-5.77], awareness about newborn danger sign [AOR=2.18; 95\% $\mathrm{Cl}: 1.29-3.68]$ and having birth preparedness and complication readiness plan [AOR=3.52; 95\% Cl: 1.97-6.29] were an identified independent factors associated with Community based newborn care Practice. Conclusion and recommendation:- Around three-fourth $(71 \%)$ of mothers were not practicing Community based newborn care. Educational status of family, awareness about community based newborn care and newborn danger sign, last delivery assisted by relative or friends at home, and having birth preparedness and complication readiness plan were identified as independent factors for community based newborn care practice. Promotion of information at community level, women empowerment and health extension program strengthening are recommending.

\section{Introduction}

Community based new born care (CBNC) is a means of bringing life-saving care to mothers and newborns at the community level within the Ethiopian health system (1). Through CBNC, the government aims to strengthen the primary health care unit (PHCU) and the Health Extension Program, which is a platform for community-based primary care delivery (1). Building on lessons learned from Integrated Community Case Management of childhood illness (ICCM), the implementation of CBNC used the following guiding principles to ensure rapid, high-quality implementation: government leadership and ownership, spanning the continuum of care, balance between preventive and curative care at the community level, quality service, community participation, strong health system support and phased implementation approach and partnership (2).

The goal of CBNC program is to reduce newborn mortality through strengthening the primary health care unit (PHCU) approach and the Health Extension Program.(3) This goal is achieved by cumulative improvement in linkages between health centers and health posts and the performance of Health 
Extension Workers (HEWs) and Women's Development Army (WDA). To improve antenatal, intrapartum, postnatal and newborn care through the "four Cs": early prenatal and postnatal Contact with the mother and newborn, Case-identification of newborns with signs of possible severe bacterial infection, Care, or treatment that is appropriate and initiated as early as possible and Completion of a full seven day course of appropriate antibiotics (3).

Globally, around 4 million neonatal deaths occur annually, which accounts for 38 percent of under-five mortality. A similar number of babies are still born and $99 \%$ of all neonatal deaths occur in low and middle income countries (4). As Ethiopian Demographic and Health Survey (EDHS) 2016, the neonatal mortality rate was 29 deaths per 1,000 live births. The risk of death is highest in the first 24 hours of life when more than half of deaths occur and about three-quarters of all neonatal deaths occur within the first week of life (5).

Despite Ethiopia's remarkable reductions in infant and under-5 mortality and achievement of Millennium Development Goal (MDG) four three years ahead of the deadline, the reduction in neonatal mortality has not been as impressive (1). The 2016 EDHS results show that the neonatal and infant death for the 5 years before the survey is $29 \& 48$ deaths per 1,000 live births, respectively. In other words, in Ethiopia 1 in every 35 children dies within the first month and 1 in every 21 children dies before celebrating the first birthday (6). Although Ethiopian government did many health interventions such as training health workers, enhancing referral system, integrating health services, implementing packages of Health Extension Program (HEP) and routine immunization, neonatal death is still high, even one of the top ten countries in Africa $(7,8)$. The finding of studies conducted in different area of Ethiopia with regards to the level of CBNC practice documented that there is low comprehensive practices of essential new born care practices $(9,10)$. A family community package promoting good home care of the newborn particularly cleanliness, warmth provision, and exclusive breastfeeding would have an expected reduction in the NMR of 10 to 40 percent, varying with the baseline NMR and the potential for accessing care. The effect might be greater if the package successfully addressed harmful local practices.

As the indication of EDHS 2016 the proportion of home delivery nearly 83\% in Ethiopia the probability of maternal and newborn health, need more investigation for better planning and promotion on maternal and newborn health. Outreach services such as prenatal care alone have an effect of about 10 percent on NMRs, but when they are combined with a family package using community health promoters, an additional 30 percent reduction in the NMR is projected in Ethiopia (11).

As indicated on 2017/2018 annual report of Segen Area People Zone maternal and newborn health report performance of ANC 4th $63 \%$, and skill delivery coverage $71 \%$ In addition to this, specific to Amaro district government report reveals that postnatal care service coverage $68 \%$, and skill delivery coverage $32.09 \%$. Therefore, obtaining evidence on level of Community on Essential Newborn Care Practices and its associated factors will facilitate the interventional measures to avert the preventable factors of neonatal death. Hence, this study aimed to assess community based essential newborn care practices 
and associated factors among women who gave birth in the last 12 months preceding the survey in Amaro woreda southern Ethiopia, 2019.

\section{Methods And Materials}

\section{Study area, Design and Period}

This study conducted in Amaro district in Segen Area Peoples Zone, Southern Ethiopia. The district is located $695 \mathrm{~km}$ south of Addis Ababa and $465 \mathrm{~km}$ still south of the regional capital city Hawassa. The district has a total of population of 193,219 in which 25,505 women are in childbearing age. In the district, there are 33 rural kebele and 2 urban kebele. In the district, there are one primary hospital, seven health centers, 39 health posts and 25 private health facilities deliver health care service (21). Health Extension workers at health posts are providing maternal, child and neonatal services like ANC, PNC, Immunization, growth monitoring, outpatient therapeutic program, ICCM/CBNC and first aids. At community level, Heath extension workers are performing preventive health services through regular home to home visits and curative services at health post $(22,23)$.

A community based descriptive cross-sectional study was conducted from January-February 2019 in Amaro district, Southern Ethiopia.

\section{Population, Sampling Determination and Sampling Procedure}

The source population was women in the reproductive age group of 15-49 years who were practicing home delivery in Amaro district. Accordingly, women of reproductive age groups who gave live birth at home in the last 12 months' period preceding the survey was taken as study population. To take adequate sample size from study population, sample size for study was determined by single population formula by consideration of a desired level of confidence (95\%), margin of error (5\%), non- response rate $(10 \%)$, design effect (1.5), the estimated prevalence of community based essential newborn care practices $(26.7 \%)$ [10]. the final sample size for this study was 495 .

To make the sample is more representative; around $31 \%$ (11) out of 35 kebeles of Amaro district were selected using lottery method. Then, proportional allocation of size to kebele was made. Finally, computer random generated number was employed to recruit the mother from family folder in community health information system. However, the mothers who delivered in the health institution, mothers who are caregivers to babies whose mother is lost, those mothers who were seriously sick during data collection and mothers who recently delivered died fetus was excluded from the study.

\section{Variables of the study and Operational definitions}

Community Based Essential Newborn Care Practices is outcome, while age of mother, education of mother, education of father; sex of neonate, occupation of mother, Occupation of father, $n$ umber of pregnancy, number of delivery, number of children, number of ANC visits, attendant at birth, birth preparedness plan, mothers awareness about newborn danger signs, counseling from a health extension worker (HEW) or advice from a CHV (WDA leader), exposure to media and husband involvement. 
Community Based Essential New Born Care Practiced: In this study those mothers who practice all the three essential new born care practices (delayed bathing, safe cord cutting and early initiation of breast feeding within one hour of birth) are said to be practiced (9).

Delayed bathing: The recommended practice of bathing a new born by delaying for at least the first 24 hours of birth to reduce the risk of hypothermia(10).

Early initiation of breast feeding: The recommended practice of putting a new born to the mother's breast within one hour of birth (10).

Safe cord cutting: Safe cord cutting means practice of cutting a new born cord with help of the instrument from clean home delivery kit, a new blade or a boiled blade (15).

\section{Data collection methods and tools}

Structured questionnaires were designed in English version and translated to Amharic and local language. Pre-test was carried out on the $10 \%$ of sample size at Burji District which is one of neighbor district and necessary correction was made prior to the actual data collection. The data was collected by four BSc graduate professional in health at selected households. Training was given for data collectors and supervisor on the objectives of the study, the content of the questionnaire, issue related to confidentiality of the responses and rights of the respondents during data collection. They also have informed about proper data handling, systematic answers for respondents' questions. data was collected by using face to face interviews. Supervisors checked data for completeness daily after data collection and principal investigator also randomly cross-checked the data before entry. Finally, the overall data collection process was controlled by the principal investigator.

\section{Data Processing and Analysis}

EpiData version 3.1. statistical software was used for data entry and cleaning, then exported to SPSS version 20 for analysis. Descriptive statistics like frequencies \& percentages were computed. Results were presented using text, tables and figures. The presence of association between dependent and independent variables was checked with odds ratio with $95 \%$ confidence intervals ( $95 \% \mathrm{Cls}$ ) and p-value less than or equal to 0.05 . Bivariate analyses were conducted and all variable which has cut of point $p$ value less than 0.2 were enter into a multiple variable logistic regression model to outline the independent predictors of the community based essential newborn care. Assumption of logistic regression: meaningful coding, normality, multicollinearity and outliers checked before final logistic regression model analysis. Multivariate outliers were checked by using cook's distance and leverage value. Multi collinearity is checked by using variance inflation factors and tolerance test. The Hosmer-Lemeshow tests and Omnibus tests of model coefficient were checked to assess goodness-of-fit model.

\section{Results}


A total 495 sampled population 490 with the response rate of $98.9 \%$ were in included in this study. Among babies participated in the study, $55.53 \%$ of were males. Concerning to ethnic groups, the Koore accounted 448 (91.8\%). Regarding to the marital status of mothers, $447(91.2 \%)$ were currently married or cohabiting and $5.1 \%$ were married but not live with husband. Mothers who had formal education and illiterate were $216(44.1 \%)$ and $141(28.8 \%)$ respectively. Protestant religion followers accounted $386(78.8 \%)$ followed by Orthodox $75(15.3 \%)$. Regarding to past 12 months' work status of Mothers of study babies, $57.1 \%$ and $33.5 \%$ of the study participants were house-wives and farmers respectively (Table 1).

\section{The Level of Essential Community Based New-born Care (CBNC) Practice}

Mothers practices of new born care, around 309 (63.1\%), 295(60.2\%) and 290 (59.2\%) of mother initiate breast-feeding immediately after birth, safe cord cutting and delayed bathing respectively (Table 2).

The overall community based newborn care practice in regard with three parameters i.e. delayed bathing for first 24 hours, safe cord cutting and early initiation of breast feeding (within one hour of birth) was $142(29 \%)$ (Figure 1)

\section{Factors Independently Associated with Essential Community Based New-born Care (CBNC) Practices}

To determined independent predictors of CBNC practice, 11 variables from socio-demographic, pregnancy \& obstetric and informational related factors having $p$-value $\leq 0.2$ on bivariate analysis were fitted into the final model. Accordingly, formal paternal education [AOR=2.28; 95\% Cl:1.07-4.84, $p<0.03$ ], mothers able to read and write [AOR $=0.35 ; 95 \% \mathrm{Cl}: 0.16-0.75, p<0.007$ ], last delivery assisted by relative or friends $[A O R=3.58 ; 95 \% \mathrm{Cl}: 1.66-7.73, p<0.001]$, having awareness about CBNC [AOR=3.49; 95\%Cl: 2.11-5.77, $p<0.001]$, awareness about newborn danger sign[AOR $=2.18 ; 95 \% \mathrm{Cl}: 1.29-3.68, p<0.004]$ and having birth preparedness and complication readiness plan [AOR=3.52; 95\% Cl: 1.97-6.29, $p<0.001$ ] were identified as independent factors associated with (CBNC) Practice. In contrast to this, ANC visits during last pregnancy, number of last fetus, early PNC for last birth by HEW and counseling about CBNC in the last 12 months were not significantly associated with Essential Community Based New-born Care (CBNC) Practice in final model (Table 3).

\section{Discussion}

This study aimed to assess community based essential newborn care practices and associated factors among women who gave birth at home in the last 12 months preceding the survey in Amaro woreda southern Ethiopia. Of the total study participants included in the analysis, 142(29\%) were practiced CBNC. However, $60.2 \%$ neonate received clean cord care, $63.1 \%$ mothers initiated breast-feeding within one hour and $59.5 \%$ received appropriate bathing, which is comparable with study conducted in Southwest Ethiopia (18). The prevalence of community based essential new-born care (CBNC) practice in this study is considered to be higher as compared to other studies reports from Amhara (23.1\%) and Aksum (26.7\%) $(9,10)$. This discrepancy may be due to the fact that some of the former studies include both home and facility delivery. 
In the current study, paternal education was found to have statistically significant association with community based essential newborn care practices. Babies born to fathers having formal education were two times more likely receiving $C B N C$ than babies born to illiterate fathers'. This finding is consistent with finding in Bangladesh [AOR=1.3], Gojam, Ethiopia [AOR=7.02], Welkite, southwest Ethiopia [AOR=1.21], (9, 17-19). This might be due to the fact that education in the real world has a positive significant effect to practice any healthy life for mothers and children as well families. However, in the current study mothers able to read and write were $65 \%$ less practicing CBNC than illiterate mothers. It need further investigation.

Mothers who had her last delivery at home by assisted with relatives or friends were found to be 3.58 times more likely practicing CBNC than those assisted by HW at home This may be due to poor quality of counseling by HEW or HWs results in strong peer pressure to change their view towards CBNC practice.

Having awareness about CBNC is the most important reported factors in the population $(15,19)$. Besides of the above reported risk factors the level of practicing the community based essential new-born care (CBNC) was 3.49 times highly common among those mothers who had awareness about CBNC than those who did not informed. This finding was consistent with finding in eastern Tigray [AOR=5.63], Aksum town $[A O R=3.36]$ and Gojam, Ethiopia $[A O R=7.9](9,10,17)$. The finding was found to be contrary to finding in Welkite town, Ethiopia [AOR=0.17] (19). This discrepancy may be due to socio-demographic and socio-cultural differences among participants in different demography of the country. Another reason for variation may be due to the time effect that study conducted.

Neonatal danger has become a substantial problem in many developing countries like Ethiopia. In this regard, health-seeking behavior of mothers for neonatal care highly relies on their knowledge about neonatal danger sign, and it has been hardly investigated (24). In this community-based study, individuals who had awareness about newborn danger sign were 2.18 times more likely practicing community based essential newborn care (CBNC) as compared to the counterpart. The finding in this study considered to be in line with a community based study conducted in Enugu state, South-East Nigeria and North West of Ethiopia $(24,25)$. This finding might be due to the fact that those mothers who had a positive awareness about neonatal danger sign experienced of how to practice CBNC.

Birth preparedness and complication readiness (BP and $\mathrm{CR}$ ) is a safe motherhood comprehensive strategy and matrix that includes shared responsibility among the woman and her family, the community, healthcare providers, facilities that serve them, and the policies that affect care for the woman and the newborn (26). Accordingly, the likelihood of Community based essential new-born care (CBNC) practice among those having birth preparedness and complication readiness plan was 3.52 more prone to practice CBNC than counterpart. This finding was in line with finding in Kofale District, South East Ethiopia (26) and it was found to be due to the fact that having birth preparedness and complication readiness plan positively affect the mothers practice to ward community based essential new born care.

Unlike many other study findings, this study did not reveal any association of community based essential new-born care (CBNC) practice with number of ANC visits during last pregnancy, number of last fetus, early PNC for last birth by HEW and counseling about CBNC in the last 12 months. This might be 
illustrated by variations related to study population, setting, socio-demographic, socio -economic and cultural difference.

One of the strength of this study was findings can be generalized to similar settings and population in other parts of the country since this study is primary data and a community based study.

\section{Conclusion}

In conclusion, around $71 \%$ of mother who give home birth and participated in this study were not practicing essential newborn care, which is fare lower than many other studies. The study identified both positive and negative factors towards to CBNC practice. Accordingly, having formal paternal educational, delivery assisted by relative or friends, having awareness about CBNC, having awareness about newborn danger sign and having birth preparedness and complication readiness plan were positively affecting an essential community based new-born Care (CBNC) Practice. However, maternal educations were negatively associated with community based essential newborn care practices. Therefore, government should take remedial action on education improvement, action should be taken to improve community knowledge on newborn danger sign, birth preparedness and complication readiness.

\section{Declaration}

\section{Ethics approval and consent to participate}

Ethical approval was obtained from institutional ethical review board of College of Medicine and Health Science Arba Minch University. A formal letter was written to the different administrative bodies and organizations to obtain permission to conduct the research in the settings then permission obtained from zonal health department to conduct this research in the setting. Finally, informed written consent was obtained from study participants before interview.

\section{Consent to publish}

Not applicable. But, we didn't taken image, voice and video recorded. By considering the benefit of the study the findings is summited for publication .

\section{Availability of data and material}

The datasets used for current study is available from the corresponding author on reasonable request.

\section{Competing interests}

The authors declare that they have no competing interests.

\section{Funding}

Not received

\section{Authors' contributions}


MA and MS design the original proposal, MS, SH, GT, GG, BT and WG were conducted analyses and interpretation. All authors were participated on discussion and recommendation part of study. MS was wrote final manuscript. Finally, all authors approved the manuscript.

\section{Acknowledgments}

Researchers would like to thanks Arba Minch University for financial contribution and also study participants, supervisors and data collectors for their contribution on the success of this research.

\section{Reference}

1. Berhanu DA, B. Community Based Newborn Care in Ethiopia: Quality of CBNC programme assessment Midline Evaluation Report March 2017. Technical Report. 2017.

2. Della Berhanu BA. Community Based Newborn Care: Quality of CBNC programme assessment - midline evaluation report, . London: March 2017.

3. FMOH. COMMUNITY BASED NEWBORN CARE TRANING FOR HEALTH EXTENSION WORKERS: FACILITATORS GUIDE. May2013.

4. S. Karger AG B, Ola Didrik Saugstad. Reducing Global Neonatal Mortality Is Possible, Department of Pediatric Research, Oslo University Hospital, Norway. Neonatology; 99: 250-257. Accessible online at: www.karger.com. /DOI: 10.1159/000320332. 2011.

5. Bogale worku MG. New born care training manual, essential new born care for every baby. Federal Ministry of Health Ethiopia EPS; August. 2012.

6. EDHS. ETHIOPIA Demographic and Health Survey 2016. Addis Ababa, Ethiopia: CSA, July 2017.

7. IV H. Health sector development plan IV; Federal Democratic Republic of Ethiopia, Minstry of Health. Addis Ababa, Ethiopia. 2014.

8. WHO. Maternal, Newborn, Child and Adolescent Health Highlights 2012-2013, Progress Report. . 2013.

9. Teshome Kokebie MA, Genet Degu. Community Based Essential New Born Care Practices and Associated Factors among Women in the Rural Community of Awabel District, East Gojjam Zone, Amhara, Ethiopia, 2013. International Journal of Advances in Scientific Research. 2015;1(01):17-27.

10. Megbey Berhe AAM, Gizienesh Kahsay, Ermyas Birhane, Mebrahtu Abay. Essential neonatal care utilization and associated factors among mothers in public health facilities of Aksum Town, North Ethiopia PLoS ONE. 2017;12:4.

11Newborn Health; More Than 4 Million Newborns Die Each Year, Even Though Effective and Inexpensive Interventions Exist: Disease control priorities project; April 200. 
12. FMOH. Community Based Newborn Care Implementation Plan. Federal Ministry of Health Ethiopia; February 2012.

13. MOH. COMMUNITY BASED NEWBORN CARE TRANING FOR HEALTH EXTENSION WORKERS. In: Program HE, editor. Addis Ababa: Minstry of Health; May2013.

14. Berhanu D. ABI. Community Based Newborn Care: Quality of CBNC programme assessment - midline evaluation report, March 2017. London: IDEAS, London School of Hygiene \& Tropical Medicine. 2017.

15. Md. Shahjahana MRA, M. Mokhlesur Rahmanc, Afsana Afroz. Factors affecting newborn care practices in Bangladesh. Paediatric and Perinatal Epidemiology. January 2012;26;:13-8.

16. Jennifer A Callaghan-Koru1* AS, Maya Tholandi3, Joseph de Graft-Johnson4, Ephrem Daniel2, Barbara Rawlins3, Bogale Worku5 and Abdullah H Baqu. Newborn care practices at home and in health facilies of 4 regions in ethiopia. BMC Pediatrics 2013;13:(198).

17. Haftom Gebrehiwot Misgna HBG, Mulugeta Molla Birhanu. Knowledge, practice and associated factors of essential newborn care at home among mothers in Gulomekada District, Eastern Tigray, Ethiopia, 2014. BMC Pregnancy and Childbirth. 2016;16(144).

18. Tura G, Fantahun M, Worku A. Neonatal care practice and factors affecting in Southwest Ethiopia: a mixed methods study. BMC international health and human rights. 2015;15:18.

19. Walellign Anmut BF, Tigist Demeke. mothers-knowledge-and-practice-about-neonatal-danger-signsand-associatedfactors-in-wolkite-town-gurage-zone-snnpr-ethiopia-2017. Journal of Biomedical Sciences. 2017;6(5):33.

20. Achamyelesh Gebretsadik AA, Million Teshome, Mekdes Mekonnen. Home-based neonatal care by Health Extension Worker in rural Sidama Zone southern Ethiopia: a cross-sectional study. Pediatric Health, Medicine and Therapeutics November 2018;2018(9):147-55

21. D.W.H. Annual Report of Derashe Woreda health office Derashe Gidole,Ethiopia 2015.

22. Ethiopia MoHTFDRo. Health SectorTransformation Plan. 2015.

23. Yaya Y DT, Lindtjørn B Maternal Mortality in Rural South Ethiopia: Out Comes of Community-Based Birth Registration by Health Extension Workers. 2015;PLoS ONE 10): (3).

24. Solomon Gedlu Nigatu1 AGWaAFD. Level of mother's knowledge about neonatal danger signs and associated factors in North West of Ethiopia: a community based study. BMC Res Notes. 2015;8(309).

25. Uchenna Ekwochi1† IKN, Chidiebere DI Osuorah2*†, Ogechukwu F Amadi1, Ifeyinwa B Okeke1, Ejike Obuoha1, Kenechi S Onah3, Ikenna Nwokoye4, Odutola I Odetunde5 and Nnenne I Obumneme-Anyim5. 
Knowledge of danger signs in newborns and health seeking practices of mothers and care givers in Enugu state, South-East Nigeria. Italian Journal of Pediatrics. 2015;41(18).

26. Adugna Tafa1 DH, Jemal Ebrahim3, Melesse Gebrie, Negash Wakgari. Birth Preparedness and Complication Readiness Plan among Antenatal Care Attendants in Kofale District, South East Ethiopia: A Cross Sectional Survey. Diversity and Equality in Health and Care. 2018;25(1):23-9.

\section{Tables}

Table 1: Socio-demographic characteristics of the study participants in Amaro District, SNNPR, Ethiopia, October-December, $2018(N=490)$

\begin{tabular}{|c|c|c|c|}
\hline Variables & Categories & $\mathbf{N}$ & $\%$ \\
\hline \multirow[b]{2}{*}{ Sex of baby } & Male & 271 & 55.3 \\
\hline & Female & 219 & 44.7 \\
\hline \multirow{3}{*}{ Age of baby } & Less than 2 months & 113 & 23.1 \\
\hline & 2 up to 6 months & 218 & 44.5 \\
\hline & More than 6 months & 159 & 32.4 \\
\hline \multirow{3}{*}{ Age of mother } & $15-24$ years & 108 & 22.0 \\
\hline & 25-34 years & 320 & 65.3 \\
\hline & $\geq 35$ years & 62 & 12.7 \\
\hline \multirow{3}{*}{ Ethnicity } & Koore & 448 & 91.4 \\
\hline & Wolyta & 22 & 4.5 \\
\hline & Others & 20 & 4.1 \\
\hline \multirow{3}{*}{ Religion } & Protestant & 386 & 78.8 \\
\hline & Orthodox & 75 & 15.3 \\
\hline & Others* & 29 & 5.9 \\
\hline \multirow{3}{*}{ Marital status of Mother } & Married and live with husband & 447 & 91.2 \\
\hline & Married but not live with husband & 25 & 5.1 \\
\hline & Others** & 18 & 3.7 \\
\hline \multirow{3}{*}{ Occupational status of Mother } & House wife & 280 & 57.1 \\
\hline & Farmer & 164 & 33.5 \\
\hline & Others*** & 46 & $9.4^{1}$ \\
\hline
\end{tabular}

${ }^{1}$ Others( Gurage, Tigray, Amhara) , Others* (Catholic and Muslim), Others** ( widowed, divorced, single) , Others*** (Merchant and Government employee). 
Table 2: Types of essential new-born Care Practices, of the study participants in Amaro District, SNNPR, Ethiopia, October-December, $2018(N=490)$

\begin{tabular}{|c|c|c|c|}
\hline Variables & Categories & Frequency & $\%$ \\
\hline \multirow{3}{*}{ New-born Bathing } & Immediately after birth & 148 & 30.2 \\
\cline { 2 - 4 } & After 24 hours & 290 & 59.2 \\
\cline { 2 - 4 } & After 2 day and above of birth & 52 & 10.6 \\
\hline \multirow{3}{*}{ Initiation of breast feeding } & Immediately after birth & 309 & 63.1 \\
\cline { 2 - 4 } & After one hours & 168 & 34.3 \\
\cline { 2 - 4 } & Others & 13 & 2.7 \\
\hline \multirow{3}{*}{ Safe Cord Cutting } & Cut with boiled blade & 295 & 60.2 \\
\cline { 2 - 4 } & Cut with un-boiled blade & 161 & 32.9 \\
\cline { 2 - 4 } & Others & 34 & 6.9 \\
\hline
\end{tabular}

Table 3: Factor Associated with CBNC practice of the study participants in Amaro District: regression models showing adjusted odds ratios, $95 \%$ confidence intervals. 


\begin{tabular}{|c|c|c|c|c|c|}
\hline \multirow[t]{2}{*}{ Variables } & \multirow[t]{2}{*}{ Category } & \multicolumn{2}{|c|}{ CBNC practiced } & \multirow{2}{*}{$\begin{array}{c}\text { AOR } \\
(95 \% \mathrm{CI})\end{array}$} & \multirow{2}{*}{$\begin{array}{c}\mathrm{P}- \\
\text { value }\end{array}$} \\
\hline & & Yes (\%) & No (\%) & & \\
\hline \multirow[t]{2}{*}{ Sex of Baby } & Male & $65(24.0)$ & $206(76.0)$ & & \\
\hline & Female & $77(35.2)$ & $142(64.8)$ & $\begin{array}{c}1.45 \\
(0.90- \\
2.33) \\
\end{array}$ & 0.12 \\
\hline \multirow[t]{3}{*}{ Educational status of mother } & Illiterate & $40(28.4)$ & 101(71.6) & \multicolumn{2}{|c|}{1} \\
\hline & read and write & $25(18.8)$ & $108(81.2)$ & $\begin{array}{c}0.35 \\
(0.16- \\
0.75)\end{array}$ & 0.007 \\
\hline & formal education & $77(35.6)$ & $139(64.4)$ & $\begin{array}{c}0.70 \\
(0.36- \\
1.38)\end{array}$ & 0.30 \\
\hline \multirow[t]{3}{*}{ Educational status of father } & Illiterate & $19(22.1)$ & $67(77.9 \%)$ & \multicolumn{2}{|c|}{1} \\
\hline & read and write & $24(20.0)$ & $96(80.0)$ & $\begin{array}{c}1.36 \\
(0.58- \\
3.21)\end{array}$ & 0.480 \\
\hline & formal education & $99(35.0)$ & 184(65.0) & $\begin{array}{c}2.28 \\
(1.07- \\
4.84)\end{array}$ & 0.033 \\
\hline \multirow[t]{4}{*}{ ANC visits during last pregnancy } & None & $43(25.3)$ & $127(74.7)$ & \multicolumn{2}{|c|}{1} \\
\hline & Once & $25(35.7)$ & $45(64.3)$ & $\begin{array}{c}1.56(0.36- \\
1.60)\end{array}$ & 0.76 \\
\hline & 2 up to 3 & $35(25.9)$ & $100(74.1)$ & $\begin{array}{l}1 . .73 \\
(0.29- \\
1.03)\end{array}$ & 0.54 \\
\hline & four times & $39(34.2)$ & $75(65.8)$ & $\begin{array}{c}2.35(0.56- \\
1.98)\end{array}$ & 1.05 \\
\hline \multirow[t]{3}{*}{ last delivery assisted by } & TBA & $25(26.6)$ & $69(73.4)$ & $\begin{array}{c}2.09 \\
(0.84- \\
5.22)\end{array}$ & 0.12 \\
\hline & Relative(friends) & $105(32.8)$ & $215(67.2)$ & $\begin{array}{c}3.58 \\
(1.66- \\
7.73)\end{array}$ & 0.001 \\
\hline & HEW/HW/Others & $12(15.8)$ & $64(84.2)$ & \multicolumn{2}{|c|}{1} \\
\hline \multirow[t]{2}{*}{ Number of last fetus } & Single & $134(28.4)$ & $338(71.6)$ & $\begin{array}{c}0.42 \\
(0.14- \\
1.27)\end{array}$ & 0.12 \\
\hline & Twin & $8(44.4)$ & 10(55.6) & & \\
\hline \multirow[t]{2}{*}{ Early PNC for last birth by HEW } & Yes & $55(37.2)$ & $93(62.8)$ & $\begin{array}{c}1.42 \\
(0.82- \\
2.46)\end{array}$ & 0.22 \\
\hline & No & $87(25.4)$ & $255(74.6)$ & \multicolumn{2}{|c|}{1} \\
\hline Information about CBNC & Yes & $77(47.5)$ & $85(52.5)$ & $\begin{array}{c}3.49 \\
(2.11-\end{array}$ & 0.001 \\
\hline
\end{tabular}




\begin{tabular}{|c|c|c|c|c|c|}
\hline & & & & 5.77) & \\
\hline & No & $65(19.8)$ & $263(80.2)$ & \multicolumn{2}{|c|}{1} \\
\hline \multirow[t]{2}{*}{$\begin{array}{l}\text { Information about newborn danger } \\
\text { sign }\end{array}$} & Yes & $67(45.6)$ & $80(54.4)$ & $\begin{array}{c}2.18 \\
(1.29- \\
3.68)\end{array}$ & 0.004 \\
\hline & No & 75 (21.9) & $268(78.1)$ & \multicolumn{2}{|c|}{1} \\
\hline \multirow[t]{2}{*}{$\begin{array}{l}\text { Counseling about CBNC in the last } 12 \\
\text { months }\end{array}$} & Yes & $67(41.6)$ & $94(58.4)$ & $\begin{array}{c}1.61 \\
(0.95-2.7)\end{array}$ & 0.07 \\
\hline & No & $75(22.8)$ & $254(77.2)$ & \multicolumn{2}{|c|}{1} \\
\hline \multirow[t]{2}{*}{$\begin{array}{l}\text { Having birth preparedness and } \\
\text { complication readiness plan }\end{array}$} & Yes & $120(37.6)$ & $199(62.4)$ & $\begin{array}{c}3.52 \\
(1.97- \\
6.29)\end{array}$ & 0.001 \\
\hline & No & $21(12.4)$ & 149(87.6) & \multicolumn{2}{|c|}{1} \\
\hline
\end{tabular}

**Significance at $\mathrm{p}_{\text {_ }}$ value $<0.001, *$ significance at $\mathrm{p}_{\text {_ }}$ value $<0.05$.

\section{Figures}

\section{CBNC Practice status of study participants}

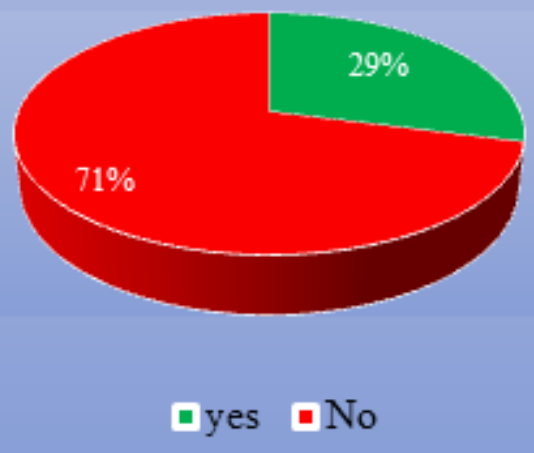

\section{Figure 1}

Community based newborn care practice status of study participants, Amaro district 